\title{
REVIEW
}

\section{Microsurgical varicocelectomy: a review}

\author{
Akanksha Mehta and Marc Goldstein
}

Varicocelectomy is the most commonly performed surgical procedure for the treatment of male infertility. Although several different techniques for varicocele repair have been described in the literature, microsurgical varicocelectomy performed through a subinguinal or inguinal incision is recognized as the gold-standard approach for varicocelectomy, due to high success rates with minimal complications. Standard indications for varicocelectomy include palpable varicocele(s), with one or more abnormal semen parameters, and, for the couple trying to conceive, in the setting of normal or correctable female infertility. However, varicocele repair is often recommended and undertaken for reasons other than infertility, including low serum testosterone, testicular pain, testicular hypotrophy and poor sperm DNA quality. This article reviews the technical aspects of microsurgical varicocelectomy, and its indications in adults and adolescents.

Asian Journal of Andrology (2013) 15, 56-60; doi:10.1038/aja.2012.98; published online 12 November 2012

Keywords: DNA fragmentation; hypogonadism; infertility; microsurgical varicocelectomy; orchalgia; varicocele repair

\section{INTRODUCTION}

Clinical varicoceles are present in approximately $15 \%$ of the general male population, and in up to $35 \%$ of men with primary infertility and $75 \%$ of men with secondary infertility. ${ }^{1}$ Varicoceles are recognized as the most common surgically correctable cause of male infertility, but the exact mechanism of varicocele-induced impairment of spermatogenesis remains a matter of debate. The majority of men with varicoceles are asymptomatic and fertile, with only 15\%-20\% experiencing physical discomfort or problems related to fertility. ${ }^{1}$ The question of whether or not the effect of varicocele on testicular function is progressive remains unresolved, despite the considerable body of literature devoted to this topic. ${ }^{2-4}$ Therefore, current challenges in the management of varicoceles lie in determining which patients stand to benefit most from surgical correction, and when surgery should be performed.

Guidelines relating to varicoceles and infertility have been put forth by the American Urological Association (AUA), ${ }^{5}$ and more recently, by the American Society of Reproductive Medicine (ASRM) ${ }^{6}$ Both reports recommend varicocele repair in cases of a clinically palpable varicocele with documented infertility, one or more abnormal semen parameters, and in the setting of normal or potentially correctable female fertility. Varicocele repair is also recommended in individuals with palpable varicoceles and abnormal semen parameters who are not actively trying to conceive, and in adolescents who have reduced ipsilateral testicular size in the setting of a palpable varicocele. In addition to abnormal semen parameters, varicoceles have been associated with abnormal sperm DNA quality, testicular hypotrophy, impaired testosterone production and testicular pain. Several authors have advocated for varicocelectomy in these settings, especially given the evidence for a progressive effect of varicocele on testicular function.

Surgical options for varicocele repair include the traditional inguinal (Ivanissevich) or high retroperitoneal (Palomo) approaches, laparoscopic repair and microsurgical repair via an inguinal or subinguinal incision. Varicocele embolization is a non-surgical option. Complications of varicocele repair include hydrocele formation, persistence of recurrence of the hydrocele and rarely, testicular atrophy. ${ }^{1}$ Although no specific recommendations exist as to the optimal surgical technique for varicocelectomy, the use of magnification to preserve lymphatics and testicular arteries is recommended. As such, microsurgical varicocelectomy is considered the gold-standard technique for varicocelectomy in both adults and adolescents, due to lower postoperative recurrence and complication rates compared to other techniques. ${ }^{7}$ A recent meta-analysis also found microsurgical varicocelectomy to be associated with higher postoperative spontaneous pregnancy rates in infertile men with clinically palpable varicoceles. ${ }^{8}$

The aim of this article is to describe the authors' approach to microsurgical varicocelectomy, and summarize the recently published literature on standard and alternative indications for varicocele repair using this technique, including infertility, sperm DNA quality, hypogonadism, testicular hypotrophy and pain.

\section{TECHNICAL ASPECTS OF MICROSURGICAL VARICOCELECTOMY}

An operating microscope allows for $\times 6$ to $\times 25$ magnification of the operating field, considerably enhancing the surgeon's visual acuity and ability for precision. Magnification allows for meticulous hemostasis, identification and preservation of testicular arteries and lymphatics, and avoidance of inadvertent iatrogenic injuries. ${ }^{9,10}$ Microsurgical varicocelectomy can be performed using either an inguinal or subinguinal incision (Figure 1). Both approaches allow elevation of the spermatic cord for improved visualization of the cord structures, provide access to external spermatic and gubernacular veins and allow delivery of the ipsilateral testicle, for biopsy or examination under the 


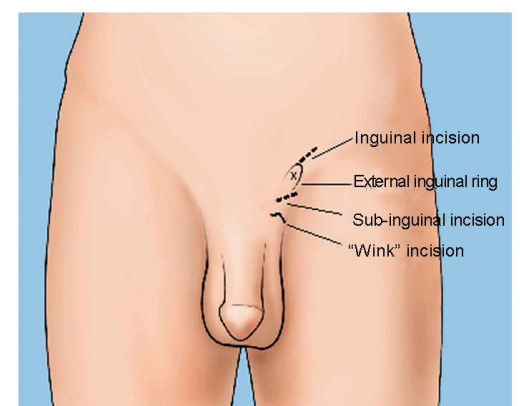

Figure 1 Incisions used for varicocelectomy. An inguinal or subinguinal approach is best suited for microsurgical varicocelectomy. This figure is reproduced with permission from Campbell-Walsh Urology. ${ }^{1}$

microscope. Because the subinguinal incision obviates the need for opening any fascial layer, it is theoretically associated with a faster and less painful recovery. The subinguinal approach is, therefore, the preferred approach at our institution.

Nevertheless, certain anatomic considerations may favor use of the inguinal approach. The subinguinal level is usually associated with a greater number of smaller diameter veins, as well as more than one branch of the testicular artery, making dissection and arterial preservation more challenging, particularly for the inexperienced microsurgeon. The use of an inguinal incision in this setting provides access to the proximal spermatic cord, where the vascular structures are larger, and less likely to have branched. Accordingly, we also prefer an inguinal incision, with opening of the external oblique, in adolescents and in thin men with a tight, low, external inguinal ring. Secondly, in patients with a recurrent varicocele that was originally treated subinguinally, use of an inguinal approach may help avoid difficult dissection in a scarred surgical field. And lastly, an inguinal incision should be used when microsurgical varicocelectomy is to be performed in conjunction with an ipsilateral hernia repair.

The following paragraphs detail the surgical technique employed by the authors. If an inguinal approach is selected, the incision is initiated at or above the external ring and extended $2-3.5 \mathrm{~cm}$ laterally, along Langer's lines. For a subinguinal approach, the incision is made along Langer's lines just below the external ring. The size of the incision may vary between $1.5 \mathrm{~cm}$ and $3 \mathrm{~cm}$, depending on whether or not delivery of the testicle is planned, and on the testicular size. Following skin incision, Camper's and Scarpa's fascia are divided using electrocautery. When an inguinal approach is selected, the external oblique aponeurosis is opened in the direction of its fibers. The ilio-inguinal nerve is identified and preserved. The spermatic cord is grasped with a Babcock clamp, placed over a penrose drain and delivered through the incision (Figure 2). In contrast, when a subinguinal approach is selected, blunt dissection using the surgeon's index finger is performed distally and proximally along the cord, deep to Scarpa's fascia, following which the cord can be easily grasped with a Babcock clamp.

The operating microscope is brought into the field. The external and internal spermatic fascias are opened under $\times 10$ magnification (Figure 2). All dissection of the cord structures is performed using a non-locking microsurgical needle holder and smooth microsurgical forceps. The cord is inspected for visible pulsations under $\times 25$ magnification. Papavarine irrigation is used to maximally dilate the arteries and help in their identification, along with a microprobe Doppler. Suspected arteries can also be tested by elevating them until they are

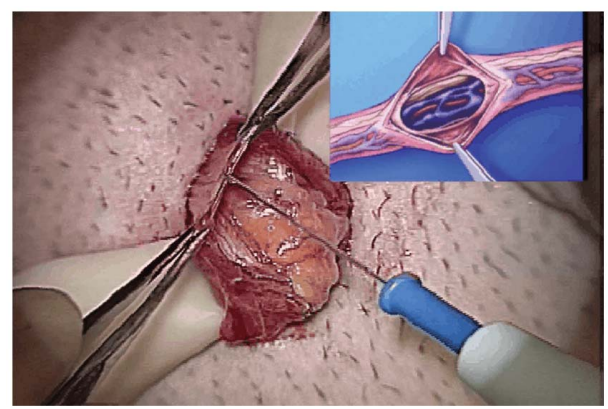

Figure 2 Exposure of spermatic cord contents after opening the external and internal spermatic fascia. This figure is reproduced with permission from Campbell-Walsh Urology. ${ }^{1}$

near-occluded, and then slowly lowering them until pulsatile blood flow is noted to have been reestablished.

Once identified and dissected free of surrounding structures, arteries are encircled with small vessel loops. In approximately $50 \%$ of cases, the testicular artery may be adherent to the undersurface of a large vein. ${ }^{11}$ Veins are stripped free of associated lymphatics, doubly ligated with hemoclips or 4-0 silk ties and divided. Small veins are controlled with bipolar electrocautery. Lymphatics, cremasteric fibers, the vas deferens and associated vasal vessels are preserved (Figure 3 ). If the vas deferens is accompanied by veins larger than $3 \mathrm{~mm}$ in diameter, these should be ligated in order to prevent varicocele recurrence. The vas is typically accompanied by two sets of vessels; as long as one of these remains intact, adequate venous return is ensured. ${ }^{1}$

Following ligation of the internal spermatic veins, venous return from the testicle is still theoretically possible via the external spermatic and gubernacular veins, and may contribute to varicocele recurrence. ${ }^{12}$ Although delivery of the testicle through the inguinal or subinguinal incision allows for inspection of all such collateral veins, the necessity of this step has been questioned by some authors. ${ }^{13}$ If delivered, identified collateral veins can easily be ligated with hemoclips and divided, leaving the gubernaculum intact for easy replacement of the testicle within the scrotum.

If opened, the external oblique aponeurosis may be closed with a continuous absorbable suture. Scarpa's and Camper's fascia are similarly reapproximated with interrupted monofilament absorbable suture. The incision is infiltrated with local anesthetic, and the skin is then closed with a 5-0 monofilament absorbable running subcuticular suture.

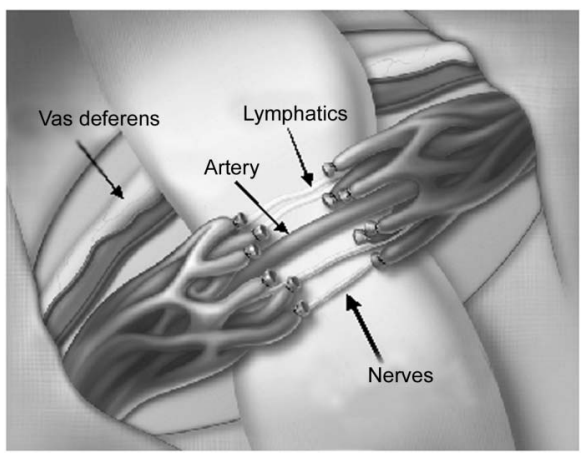

Figure 3 All visible spermatic veins are ligated while the vas deferens, associated vasal vessels, lymphatics, nerves and cremasteric fibers are preserved. 


\section{INDICATIONS FOR VARICOCELECTOMY: INFERTILITY}

Previous reviews and meta-analyses have drawn conflicting conclusions regarding the fertility-related outcomes of varicocelectomy. Published literature on this topic is heterogeneous in terms of study design, patient selection criteria, follow-up strategies and reporting of fertility-related outcomes, making it difficult to compare results. Prospective, randomized controlled trials (RCTs) evaluating the impact of varicocelectomy are limited in number, in part due to significant recruitment challenges. A multicenter, National Institutes of Health-supported RCT examining the effect of varicocelectomy on pregnancy and live birth rates was recently stopped after recruiting only three patients over a 2.5 -year time period. ${ }^{14}$ The relationship between varicocele and infertility has nevertheless continued to be closely examined in the published literature.

In a meta-analysis of 14 studies comparing pre- and postoperative semen parameters following varicocelectomy performed via either the high ligation, inguinal or subinguinal approach, Schauer et al. ${ }^{15} \mathrm{docu}-$ mented significant and comparable improvements in sperm concentration and motility, regardless of surgical technique. Similar improvements in postoperative semen parameters have been reported by others. ${ }^{16-18}$ Semen parameters improve by 3 months following varicocelectomy, with little additional improvement thereafter. ${ }^{19}$

Although numerous observational studies have documented higher pregnancy rates following varicocelectomy $v s$. observation, only two RCTs published during the past 18 months provide more conclusive evidence supporting a beneficial impact of varicocelectomy on reproductive outcomes. Abdel-Meguid et al. ${ }^{18}$ randomized 145 men with clinical varicoceles to microsurgical varicocelectomy or observation, and reported significantly improved semen parameters and higher spontaneous pregnancy rates in the treatment vs. control groups (33\% vs. 14\%). A second group of authors similarly reported significantly higher pregnancy rates in 136 men randomized to varicocelectomy vs. expectant management (44\% vs. 19\%), along with significantly lower rates of first-trimester miscarriage (13\% vs. $69 \%$, respectively). ${ }^{20}$ These findings have also been echoed in the metaanalysis by Schauer et al., ${ }^{15}$ which includes studies published between 1975 and 2011. Interestingly, Pham and Sandlow ${ }^{21}$ have shown that the improvement in semen parameters or pregnancy rates following varicocelectomy is independent of patients' body mass index.

Evidence for varicocelectomy to prevent progressive testicular dysfunction remains conflicting. The hypothesis that varicoceles have a progressive deleterious effect on testicular function derives from the higher incidence of varicoceles noted among men presenting for secondary compared to primary infertility., ${ }^{3,22,23}$ This hypothesis has been refuted by Jarow et al., ${ }^{24}$ who reported similar rates of varicocele detection in men with primary vs. secondary infertility. Although two recent studies have suggested that the duration of infertility may affect the degree of improvement in semen parameters and pregnancy rates following varicocelectomy, these studies have been retrospective, lacked control groups and failed to address confounding factors. ${ }^{25,26}$

The role of varicocelectomy in the treatment of non-obstructive azoospermia (NOA) is also controversial. The published literature suggests that $10 \%-40 \%$ of men with NOA may recover enough sperm in the ejaculate to avoid testicular sperm extraction, while improved testicular sperm production in the remainder may enhance testicular sperm extraction sperm retrieval rates. ${ }^{22}$ One recent study examining the predictors of sperm recovery in men with NOA following microsurgical varicocelectomy found sperm in the ejaculate of men with hypospermatogenesis and late maturation arrest, but not with sertoli cell-only or early maturation arrest histology, ${ }^{27}$ which echoes earlier findings. ${ }^{28}$ Overall, sperm were present in $32 \%$ of patients, but persisted on sequential semen analyses in only $19 \%$ of cases. ${ }^{27}$

The repair of clinical varicoceles appears to have a definite beneficial impact on improvement of semen parameters and spontaneous pregnancy rates. Further studies are needed to define the role of varicocelectomy in the setting of NOA, as well as long-standing varicoceles.

\section{DNA FRAGMENTATION}

Varicoceles have been associated with increased levels of reactive oxygen species and decreased seminal antioxidant capacity, increased sperm DNA damage and defective spermatogenesis in affected patients. ${ }^{29,30}$ Sperm DNA damage, in turn, has been linked to lower rates of spontaneous conception, as well as assisted reproductive pregnancies. ${ }^{31,32}$ Although oxidative stress is believed to be one possible mechanism by which varicoceles cause impaired spermatogenesis, a cause-and-effect relationship between varicoceles and DNA damage has not been firmly established. Several studies have shown similar levels of sperm DNA damage in infertile men with or without varicoceles, making it difficult to attribute sperm DNA damage to the varicocele rather than the infertility per se. ${ }^{29}$

Nevertheless, several recent studies have documented a beneficial effect of varicocelectomy on sperm DNA quality. In a prospective study of 25 infertile men who underwent microsurgical varicocelectomy, Zini et al. ${ }^{33}$ reported significant postoperative improvements in percentage DNA fragmentation index and percentage high DNA stainability, which are indices of sperm DNA integrity and chromatin compaction, respectively. Similar findings have been reported by others. ${ }^{17,34,35}$ Additionally, la Vignera et al. ${ }^{17}$ have noted a decrease in sperm apoptosis markers in series of 30 men who underwent varicocelectomy, presumably indicating improved sperm quality.

Sperm mitochondrial DNA copy number is inversely related to male fertility. During spermiogenesis, there is normally a sharp reduction in sperm mitochondrial DNA content. ${ }^{36}$ It has been postulated that higher than normal numbers of mitochondria in mature sperm may be linked to increased oxidative stress. ${ }^{37,38}$ A prospective pilot study of 14 men undergoing microsurgical varicocelectomy has recently demonstrated a postoperative improvement in DNA fragmentation index and high DNA stainability, along with a significant decrease in sperm mitochondrial DNA copy number, ${ }^{36}$ thereby providing an additional mechanism for the beneficial effect of varicocelectomy on male fertility.

Taken together, these findings suggest that varicocelectomy improves both spermatogenesis and spermiogenesis. Impaired DNA fragmentation may be considered an alternative indication for varicocele repair. However, supporting data from RCTs are lacking.

As such, the AUA and ASRM currently do not recommend routine clinical use of sperm DNA testing.

\section{LOW SERUM TESTOSTERONE}

Data from human and animal studies have previously shown a negative impact of varicoceles on Leydig cell function. ${ }^{22}$ Men with clinical varicoceles have been shown to have lower testosterone levels at every age, when compared to a fertility-proven control group of vasectomy reversal patients without varicoceles. ${ }^{39}$

Emerging evidence demonstrates a beneficial effect of varicocelectomy on increases in serum testosterone, regardless of patient age or laterality of varicocele. ${ }^{39-41}$ In the series by Tanrikut et al., ${ }^{39}$ approximately $70 \%$ of patients who underwent microsurgical varicocelectomy had an increase in serum testosterone levels postoperatively, by an average of $100 \mathrm{ng} \mathrm{dl}^{-1}$. These findings have been echoed by a 
prospective study of 200 men divided equally between varicocelectomy and observation groups, in which testosterone increased by an average of $80 \mathrm{ng} \mathrm{dl}^{-1}$ following microsurgical varicocelectomy, resulting in normalization of total testosterone levels in $78 \%$ of treated men vs. $16 \%$ of controls. ${ }^{42}$ Similarly, a recent meta-analysis of nine studies published between 1995 and 2011, involving 814 patients, has shown an approximate $100 \mathrm{ng} \mathrm{dl}^{-1}$ increase in serum testosterone following varicocelectomy. ${ }^{43}$ Unfortunately, the vast majority of these studies have been retrospective, and the only study to include a control group was not a randomized trial.

Based on the above data, varicocelectomy has nevertheless been proposed as an option for the prevention and treatment of low serum testosterone, even in men with semen parameters in the normal range. But longitudinal data on the long-term maintenance of higher testosterone levels following varicocelectomy, possibly obviating the need for exogenous testosterone supplementation, are not yet available.

\section{PAIN}

Although testicular pain has long been associated with varicocles, the majority of patients do not present with this complaint. Varicoceleassociated pain is usually described as a dull ache or 'scrotal heaviness' in the ipsilateral testis, which is aggravated by standing or physical activity, and alleviated by lying supine. It is usually only seen in men with large varicoceles. First line of therapy consists of conservative measures such as rest and scrotal support, and exclusion of alternative causes of scrotal pain, prior to consideration of varicocelectomy.

Several authors have described successful resolution of varicoceleassociated pain following varicocele ligation. While laparoscopic ${ }^{44}$ and robotic-assisted ${ }^{45}$ approaches have been described for this indication, most contemporary studies use a microsurgical subinguinal approach. Reported success rates vary between $50 \%$ and $90 \%$, depending on the definition used. ${ }^{46-49}$ Varicocele grade, ${ }^{47}$ preoperative duration of pain ${ }^{49}$ and quality of pain ${ }^{46}$ have been found to be predictors of postvaricocelectomy pain resolution in different series.

Despite the number of studies examining the effect of varicocelectomy on testicular pain, none have evaluated the potential placebo effect of varicocele repair on pain, or compared the results of varicocelectomy with an alternative procedure such as dissection and denervation of the spermatic cord. Instead, due to high patient-reported success rates, varicocelectomy continues to be regarded as an indication for the treatment of classical varicocele-associated pain.

\section{ADOLESCENT VARICOCELES}

Management of the adolescent varicocele remains one of the most interesting and controversial topics in pediatric urology. Microsurgical varicocelectomy is a safe and effective technique for use in the adolescent population. ${ }^{50,51}$ The procedure is similar to that performed in the adult population. Unlike adults, the fertility potential of adolescents is usually unknown at the time of presentation, necessitating a selective approach to surgical intervention. Varicocele grade, testicular disproportion and the potential for 'catch-up' growth during adolescence have all been previously proposed as criteria for adolescent varicocele repair. However, there are nuances to these criteria. A recent study noted no significant difference in semen parameters between adolescents with grade II $v s$. grade III varicoceles, indicating that high grade of varicocele alone is not a sufficient indication for surgical correction. $^{52}$

Varicoceles are associated with ipsilateral testicular hypotrophy, but the testicular volume differential that is significant enough to warrant varicocelectomy has been a matter of debate. The most recent meta-analysis on this topic examined 14 studies involving 1475 patients, and found a definitive advantage to varicocelectomy in reducing testicular hypotrophy when intertesticular size discrepancy was $\geqslant 10 \% .{ }^{53}$ Unlike previous studies, which have favored a size discrepancy of $\geqslant 20 \%$ as an indication for varicocelectomy, this meta-analysis did not take into account semen parameters, which have been shown to be largely normal at testicular volume differentials between $10 \%$ and $20 \%{ }^{54}$

The concept of catch-up growth is complex. Catch-up growth has been shown to occur after varicocele ligation, independent of the patient's Tanner stage or age, but can occur spontaneously in a significant proportion of adolescents with unrepaired varicoceles. ${ }^{55}$ There is no concrete evidence to suggest that waiting for a few years to correct an adolescent varicocele results in worse functional outcomes. Therefore, it is recommended that testicular disproportion be observed for at least 1 year to allow for spontaneous catch-up growth, prior to surgical intervention. ${ }^{55}$

One recent study evaluated sperm function after varicocelectomy in adolescent boys with grade II-III varicoceles, by comparing pre- and postoperative semen samples, and found that varicocele repair was associated with decreased levels of sperm DNA fragmentation and improved sperm mitochondrial activity. ${ }^{56}$ How the results of this and other future studies will impact the indications for varicocelectomy in the adolescent population remains to be determined.

According to expert opinion, a normal semen analysis trumps a testicular volume differential, and justifies an observational approach in adolescents with varicoceles. ${ }^{55}$ Accordingly, AUA guidelines recommend that adolescents with a palpable varicocele and normal ipsilateral testicular size be followed annually with objective assessment of testicular size and/or semen analyses. ${ }^{5}$ Deterioration in semen parameters, significant and persistent ipsilateral testicular hypotrophy in adolescents who are unable to provide a semen sample, or classic varicocele-associated pain, should be used as the primary indications for surgical intervention.

\section{CONCLUSION}

Fertility is the overriding consideration in the management of varicoceles, and varicocelectomy remains the most commonly performed surgical procedure in the treatment of male infertility. However, varicocele repair is often recommended and undertaken for reasons other than infertility, including pain, low serum testosterone and poor DNA sperm quality. Despite strong evidence of the multiple potential benefits of varicocelectomy, well-designed, randomized studies have not been performed to precisely define the benefits of varicocelectomy for men who meet the criteria for alternative indications for varicocele repair. Given the research interest and growing literature on this topic, we hope that future studies will overcome previous methodological flaws.

\section{COMPETING FINANCIAL INTERESTS}

The authors declare no competing financial interests.

Supplementary surgery video accompanies this paper on Asian Journal of Andrology's website (http://www.nature.com/aja).

1 Goldstein M. Surgical management of male infertility, In: Wein A, Kavoussi LR, Novick AC, Partin AW, Peters CA, editors. Campbell-Walsh Urology. Philadelphia, PA: Elsevier Saunders; 2012. pp648-87.

2 Jarow JP. Effects of varicocele on male fertility. Hum Reprod Update 2001; 7: 59-64.

3 Gorelick JI, Goldstein M. Loss of fertility in men with varicocele. Fertil Steril 1993; 59: 613-6. 
4 Lund L, Larsen SB. A follow-up study of semen quality and fertility in men with varicocele testis and in control subjects. BJU 1998; 82: 682-6.

5 AUA. Report on varicocele and infertility: an AUA best practice policy and ASRM Practice Committee report. AUA, Linthicum, MD, USA, 2001

6 Practice Committee of American Society for Reproductive Medicine. Report on varicocele and infertility. Fertil Steril 2008; 90(5 Suppl): S247-9.

7 Mirilas $P$, Mentessidou A. Microsurgical subinguinal varicocelectomy in children, adolescents, and adults: surgical anatomy and anatomically justified technique. $J$ Androl 2012; 33: 338-49.

8 Cayan S, Shavakhabov S, Kadioglu A. Treatment of palpable varicocele in infertile men: a meta-analysis to define the best technique. J Androl 2009; 30: 33-40.

9 Cayan S, Kadioglu TC, Tefekli A, Kadioglu A, Tellaloglu S. Comparison of results and complications of high ligation surgery and microsurgical high inguinal varicocelectomy in the treatment of varicocele. Urology 2000; 55: 750-4.

10 Chan PT, Wright EJ, Goldstein M. Incidence and postoperative outcomes of accidental ligation of the testicular artery during microsurgical varicocelectomy. J Urol 2005; 173: 482-4

11 Beck EM, Schlegel PN, Goldstein M. Intraoperative varicocele anatomy: a macroscopic and microscopic study. J Urol 1992; 148: 1190-4.

12 Kaufman SL, Kadir S, Barth KH, Smyth JW, Walsh PC et al. Mechanisms of recurrent varicocele after balloon occlusion or surgical ligation of the internal spermatic vein. Radiology 1983; 147: 435-40.

13 Ramasamy R, Schlegel PN. Microsurgical inguinal varicocelectomy with and without testicular delivery. Urology 2006; 68: 1323-6.

14 Trussell JC, Christman GM, OhI DA, Legro RS, Krawetz SA et al. Recruitment challenges of a multicenter randomized controlled varicocelectomy trial. Fertil Steril 2011; 96: 1299-305.

15 Schauer I, Madersbacher S, Jost R, Hubner WA, Imhof M. The impact of varicocelectomy on sperm parameters: a meta-analysis. J Urol 2012; 187: 1540-7.

16 Baazeem A, Belzile E, Ciampi A, Dohle G, Jarvi K et al. Varicocele and male factor infertility treatment: a new meta-analysis and review of the role of varicocele repair. Eur Urol 2011; 60: 796-808.

17 la Vignera S, Condorelli R, Vicari E, D'Agata R, Calogero AE. Effects of varicocelectomy on sperm DNA fragmentation, mitochondrial function, chromatin condensation, and apoptosis. J Androl 2012; 33: 389-96.

18 Abdel-Meguid TA, Al-Sayyad A, Tayib A, Farsi HM. Does varicocele repair improve male infertility? An evidence-based perspective from a randomized, controlled trial. Eur Urol 2011; 59: 455-61.

19 Al Bakri A, Lo K, Grober E, Cassidy D, Cardoso JP et al. Time for improvement in semen parameters after varicocelectomy. J Urol 2012; 187: 227-31.

20 Mansour Ghanaie M, Asgari SA, Dadrass N, Allahkhah A, Iran-Pour E et al. Effects of varicocele repair on spontaneous first trimester miscarriage: a randomized clinical trial. Urol J 2012; 9: 505-13.

21 Pham KN, Sandlow JI. The effect of body mass index on the outcomes of varicocelectomy. J Urol 2012; 187: 219-21.

22 Schlegel PN, Goldstein M. Alternate indications for varicocele repair: non-obstructive azoospermia, pain, androgen deficiency and progressive testicular dysfunction. Fertil Steril 2011; 96: 1288-93.

23 Witt MA, Lipshultz LI. Varicocele: a progressive or static lesion? Urology 1993; 42: $541-3$

24 Jarow JP, Coburn M, Sigman M. Incidence of varicoceles in men with primary and secondary infertility. Urology 1996; 47: 73-6.

25 Al-Ghazo MA, Ghalayini IF, AI-Azab RS, Bani-Hani I, Daradkeh MS. Does the duration of infertility affect semen parameters and pregnancy rate after varicocelectomy? A retrospective study. Int Braz J Urol 2011; 37: 745-50.

26 Hassanzadeh-Nokashty K, Yavarikia P, Ghaffari A, Hazhir S, Hassanzadeh M. Effect of age on semen parameters in infertile men after varicocelectomy. Ther Clin Risk Manag 2011; 7: 333-6.

27 Abdel-Meguid TA. Predictors of sperm recovery and azoospermia relapse in men with nonobstructive azoospermia after varicocele repair. J Urol 2012; 187: 222-6.

28 Weedin JW, Khera M, Lipshultz LI. Varicocele repair in patients with nonobstructive azoospermia: a meta-analysis. J Urol 2010; 183: 2309-15.

29 Zini A, Dohle G. Are varicoceles associated with increased deoxyribonucleic acid fragmentation? Fertil Steril 2011; 96: 1283-7.

30 Mancini A, Festa R, Raimondo S, Silvestrini A, Giacchi E et al. Biochemical alterations in semen of varicocele patients: a review of the literature. Adv Urol 2012; 2012 903931.
31 Giwercman A, Lindstedt L, Larsson M, Bungum M, Spano M et al. Sperm chromatin structure assay as an independent predictor of fertility in vivo: a case-control study. Int J Androl 2010; 33: e221-7.

32 Bungum M, Humaidan P, Axmon A, Spano M, Bungum L et al. Sperm DNA integrity assessment in prediction of assisted reproduction technology outcome. Hum Reprod 2007; 22: 174-9.

33 Zini A, Azhar R, Baazeem A, Gabriel MS. Effect of microsurgical varicocelectomy on human sperm chromatin and DNA integrity: a prospective trial. Int J Androl 2011; 34: 14-9.

34 Sadek A, Almohamdy AS, Zaki A, Aref M, Ibrahim SM et al. Sperm chromatin condensation in infertile men with varicocele before and after surgical repair. Fertil Steril 2011; 95: 1705-8.

35 McGill J, Baker K, Sharma R, Agarwal A, Sabanegh ES Jr. Effect of microsurgical varicocele ligation on sperm dna fragmentation, sperm concentration, and total motile sperm count in subfertile men, Proceeding of the AUA Annual Meeting 2012; 19-23 May 2012; Atlanta, GA, USA. Abstract 1991

36 Gabriel MS, Chan SW, Alhathal N, Chen JZ, Zini A. Influence of microsurgical varicocelectomy on human sperm mitochondrial DNA copy number: a pilot study. I Assist Reprod Genet 2012; 29: 759-64.

37 Liu CS, Tsai CS, Kuo CL, Chen HW, Lii CK et al. Oxidative stress-related alteration of the copy number of mitochondrial DNA in human leukocytes. Free Radic Res 2003; 37: 1307-17.

38 Lee $\mathrm{HC}$, Yin PH, Lu CY, Chi CW, Wei YH. Increase of mitochondria and mitochondrial DNA in response to oxidative stress in human cells. Biochem J 2000; 348(Pt 2): 425-32.

39 Tanrikut C, Goldstein M, Rosoff JS, Lee RK, Nelson CJ et al. Varicocele as a risk factor for androgen deficiency and effect of repair. BJU Int 2011; 108: 1480-4.

40 Tanrikut C, McQuaid JW, Goldstein M. The impact of varicocele and varicocele repair on serum testosterone. Curr Opin Obstet Gynecol 2011; 23: 227-31.

41 Hsiao W, Rosoff JS, Pale JR, Greenwood EA, Goldstein M. Older age is associated with similar improvements in semen parameters and testosterone after subinguinal microsurgical varicocelectomy. J Urol 2011; 185: 620-5.

42 Sathya Srini V, Belur Veerachari S. Does varicocelectomy improve gonadal function in men with hypogonadism and infertility? Analysis of a prospective study. Int J Endocrinol 2011; 2011: 916380

43 Li F, Yue H, Yamaguchi K, Okada K, Matsushita K et al. Effect of surgical repair on testosterone production in infertile men with varicocele: a meta-analysis. Int J Urol 2012; 19: 149-54.

44 Maghraby HA. Laparoscopic varicocelectomy for painful varicoceles: merits and outcomes. J Endourol 2002; 16: 107-10.

45 Parekattil SJ, Brahmbhatt JV. Robotic approaches for male infertility and chronic orchialgia microsurgery. Curr Opin Urol 2011; 21: 493-9.

$46 \mathrm{Kim}$ HT, Song PH, Moon KH. Microsurgical ligation for painful varicocele: effectiveness and predictors of pain resolution. Yonsei Med J 2012; 53: 145-50.

$47 \mathrm{Kim} \mathrm{SO}$, Jung H, Park K. Outcomes of microsurgical subinguinal varicocelectomy for painful varicoceles. J Androl 2012; 33: 872-5.

48 Armagan A, Ergun O, Bas E, Oksay T, Kosar A. Long-term effects of microsurgical varicocelectomy on pain and sperm parameters in clinical varicocele patients with scrotal pain complaints. Andrologia 2012; 44(Suppl 1): 611-4.

49 Park HJ, Lee SS, Park NC. Predictors of pain resolution after varicocelectomy for painful varicocele. Asian J Androl 2011; 13: 754-8.

50 Silveri M, Adorisio O, Pane A, Colajacomo M, de Gennaro M. Subinguinal microsurgical ligation-its effectiveness in pediatric and adolescent varicocele. Scand J Urol Nephrol 2003; 37: 53-4.

51 Lemack GE, Uzzo RG, Schlegel PN, Goldstein M. Microsurgical repair of the adolescent varicocele. J Urol 1998; 160: 179-81.

52 Mori MM, Bertolla RP, Fraietta R, Ortiz V, Cedenho AP. Does varicocele grade determine extent of alteration to spermatogenesis in adolescents? Fertil Steril 2008; 90: 1769-73.

53 Li F, Chiba K, Yamaguchi K, Okada K, Matsushita K et al. Effect of varicocelectomy on testicular volume in children and adolescents: a meta-analysis. Urology 2012; 79: 1340-5.

54 Diamond DA, Zurakowski D, Bauer SB, Borer JG, Peters CA et al. Relationship of varicocele grade and testicular hypotrophy to semen parameters in adolescents. J Urol 2007; 178: 1584-8.

55 Diamond DA, Gargollo PC, Caldamone AA. Current management principles for adolescent varicocele. Fertil Steril 2011; 96: 1294-8

56 Lacerda JI, del Giudice PT, da Silva BF, Nichi M, Fariello RM et al. Adolescent varicocele: improved sperm function after varicocelectomy. Fertil Steril 2011; 95: 994-9. 